\title{
The Filipino Seafarers' Lived Experiences Aboard International Shipping Vessels: A Basis for Health Promotion Intervention
}

\author{
Ernesto R. Gregorio, Jr.
}

Department of Health Promotion and Education, College of Public Health, University of the Philippines Manila

\begin{abstract}
Objective. This study documented the Filipino seafarers' lived experiences related to their health conditions, access to available health services and facilities, satisfaction with these, and their coping mechanisms aboard international shipping vessels.

Method. Descriptive phenomenology was used with 12 Filipino seafarers. In-depth interviews were done in an industrial clinic in Manila port area during their annual medical examinations.

Results. The most common health-related problems mentioned by informants from dry cargo bulk/tanker vessels were sexuallytransmitted infections, hypertension, accidents, heart attack, and homesickness. Hypertension, back, knee, and muscle pains and liver enzymes elevations were frequently mentioned problems in luxury liners. Circumstances on board like unlimited amount of food servings, lack of control over food choices, and negative attitude of the cook were perceived to increase seafarers' vulnerability to lifestyle diseases. Loneliness seemed to have contributed to their propensity to engage in high-risk sex behaviors. Informants reported having access to health services and facilities on board as well as satisfaction with these. Gym facilities were seldom used because of work fatigue. Coping mechanisms included watching DVDs, singing karaoke, playing video games, listening to music, and fishing.
\end{abstract}

Conclusion. Despite the reported access to health information and services, informants still reported occupational and lifestylerelated diseases that were perceived to be associated with the work situation that requires appropriate health promotion strategies.

Key Words: seafarers, maritime workers, lived experience, phenomenology, health promotion, lifestyle-related diseases, occupational health and disease

\section{Introduction}

Seafarers, also referred to as seamen, are typically male workers who work for a minimum of six months aboard shipping vessels that travel in the high seas. Supplying more

\footnotetext{
Corresponding author: Ernesto R. Gregorio, Jr., MPH

Department of Health Promotion and Education

College of Public Health

University of the Philippines Manila

625 P. Gil St., Ermita, Manila 1000 Philippines

Telephone: +632 5260811

Email: junr.gregorio@yahoo.com
}

than $20 \%$ of the world's maritime workforce, the Philippines remains to be the top source country for seafarers. Seafarers constitute more than a quarter of the 1.5 million Overseas Filipino Workers (OFWs) who helped maintain the stability and growth of the Philippine economy in 2011. In fact, remittances from sea-based OFWs alone reached a record high of US\$ 4.34 billion which was $12 \%$ higher than what was remitted in $2010 .{ }^{1}$

Factors such as low labor costs, competence in the English language, and better work habits contribute to the high demand for Filipino seafarers. ${ }^{2}$ Hence, the Philippines is projected to supply this demand for seafarers globally in the next 10 years. $^{3}$

However, several studies have shown that seafaring occupation had a higher mortality compared to other working groups. ${ }^{4,5,6}$ They hurdle work-related challenges such as loneliness, boredom, overwork and injuries due to a hazardous working environment just to support their loved ones. ${ }^{7,8}$ Furthermore, several studies and reports have likewise shown that Filipino seafarers are more prone to chronic diseases and sexually-transmitted infections (STIs) because of their unique work situation.9,10,11,12 This was exacerbated by demoralization due to perceived double standards of treatment favoring European crews who allegedly have better working conditions and regular work shifts. ${ }^{13}$

The economic contributions and documented workrelated concerns of this workforce make it imperative to give attention to their health, safety and well being.

There is a dearth of qualitative information available on Filipino seafarers' perceptions about their lived experiences aboard international shipping vessels. Certain aspects of their work situation such as long periods of isolation, long working hours, occupational hazards and stress can increase their vulnerability to work and lifestyle-related diseases. Information about their lived experiences may serve as basis for health promotion and education intervention that can reduce their vulnerabilities. Therefore, this study was undertaken to document Filipino seafarers' lived experiences in international shipping vessels, specifically their health conditions, access to available health services and facilities, their satisfaction with these, and their coping mechanisms. 


\section{Methods}

\section{Research Design}

The study used a descriptive phenomenology to describe the lived experiences of seafarers while aboard international shipping vessels. Phenomenologic research is a qualitative research technique developed by Husserl in 1970 to discover the meaning of people's life experiences. The goal of this inquiry is to fully describe lived experiences and perceptions to which it gives rise. ${ }^{14}$

\section{Study Site}

Data collection was done in an industrial clinic located in Manila port area during their pre-employment and medical examination (PEME). Interviewing the informants at their actual workplace was not feasible due to logistical and financial constraints. This industrial clinic is one of the biggest providers of PEME services for Filipino seafarers that work in various international shipping companies. It was purposively selected based on the approval and cooperativeness of the management of the industrial clinic.

\section{Study Informants, Data Collection and Analysis}

Purposive sampling was used as it is one of the most common and appropriate sampling strategies in qualitative research. ${ }^{15}$ The selection of informants was guided by the following criteria: male seafarer, must have provided written consent, at least 18 years old, and must have worked as seafarers for at least six months at the time of the interview. Each informant was approached in between waiting periods of their PEME. Data was collected through in-depth interviews with the use of a topic guide which contained mostly open-ended questions that pertain to the study objectives. To ensure privacy and minimum interference with the regular clinic activities, each interview was done in a secluded area of the clinic during long waiting periods. A total of 12 informants who met the inclusion criteria were included in the study. Recruitment was stopped on the $12^{\text {th }}$ informant when informational redundancy or data saturation was noted by the researcher during the interview and preliminary data analysis. ${ }^{16} \quad$ Data was transcribed verbatim with emerging themes and actual quotations from the informants were extracted in the succeeding analysis. Responses including quotations were collected in the vernacular and later translated to English.

\section{Results}

\section{Socio-demographic Data}

There were a total of 12 informants who participated in the study. More than half (58\%) worked in either dry cargo/bulk carriers and tanker vessels while the rest were employed in passenger luxury liners. Informants' age ranged from 25 to 51 with a mean of 37 years old. Majority were married. The length of work ranged from 1 to 17 years with an average of 9 years. Among those from dry cargo bulk/tanker vessels, majority worked as able-bodied seaman, followed by oiler, electrician, messman, ordinary seaman, chiefmate or an engineer. Majority of those working in passenger luxury liners worked as waiters and stateroom/cabin crews. Most of the informants were graduates of maritime degree courses.

\section{Emerging Themes}

The five major themes that emerged from the informants' responses were:

- Common health problems experienced by seafarers;

- High propensity for an unhealthy diet;

- Accessibility of health services and facilities;

- High satisfaction with health services and facilities; and

- $\quad$ Strong coping mechanisms and other psychosocial support.

\section{Common Health Problems Experienced by Seafarers}

The informants were asked about the health problems common among seafarers. Results revealed a variety of occupational and lifestyle-related diseases perceived to be common among seafarers. Most admitted personally experiencing at least one of these health problems and/or had personally observed some problems actually occurring on board e.g. injuries or heart attack.

The most frequent health problems mentioned by those working in dry cargo bulk/tanker vessels were sexuallytransmitted infections (STIs) such as herpes and gonorrhea.

Following were verbatim responses of informants when asked for the reasons why seafarers get these health problems:

"Whenever the ship docks, the women [female sex workers] run after us, the women in Brazil look like our local actresses here [in the Philippines].

"Even in local ports in the Philippines like in Pangasinan, Cebu, Batangas Cities, there were women who entered the ship and offered commercial sex. The same was true even in Singapore and Thailand, in Thailand, women were already queued up as the ship arrives".

It was also noted from a number of informants that sex trade on board the ship ceased when maritime rules disallowed entry of commercial sex workers following September 11 terrorists attacks in the US. However, this prohibition did not prevent seafarers from acquiring sexual services in commercial sex establishments at docking points.

STIs were commonly mentioned by those who worked in dry cargo bulk/tanker vessels but not among informants from the passenger luxury liners. Apart from STIs, there were other health problems mentioned to be common 
among seafarers. These included accidents such as burns, hypertension, heart attack, fever, homesickness/boredom, asphyxia and common colds. It was also noted that complacency of some seafarers actually placed them at risk for accidents as claimed by one informant below:

\section{Asphyxia is caused by low oxygen level below [the ship]. Seafarers knew how to detect if oxygen level is low, there was also a gauge to measure oxygen level. However, sometimes the seafarers did not look at the gauge and just estimated the oxygen level because they were used to such practice."}

Informants mentioned other health problems of seafarers but of lesser frequency and these included: muscle and back pains, diarrhea, fatigue, "Tanker Effect", burn, skin asthma, etc. When the informant who mentioned "Tanker Effect" was asked to describe the condition, he mentioned that...

\section{"The illness was common among those chronically exposed to fumes, usually those who have been working as seafarers for a long time. It was said to be manifested by absent- mindedness, irritability and having blank stares, or showing signs of insanity."}

On the other hand, those working in passenger luxury liners reported hypertension, back, knee, and muscle pains due to prolonged standing or lifting of heavy objects as well as SGPT elevations. Other ailments mentioned included diarrhea due to Norwalk Virus, varicose veins, high blood sugar, etc. Some of the actual responses pertaining to illnesses or health conditions common among seafarers were quoted as follows:

"Boredom, stomach problem, cough, fever, STIs, swollen sex organ, cold air penetrating the stomach which sometimes led to nausea, and accident. Just like what happened to the second cook, whose finger was accidentally cutoff during food preparation, what he did was to wash the finger, put it back and wrapped with gauze pad, then he waited to be brought to the nearest hospital after docking which took weeks later that caused his cut finger to rot."

"Heart attack, back and hip pain, accidents like decapitation of lower limb, getting stuck in ropes, and high cholesterol."

Hypertension was commonly mentioned in both groups and informants were also aware that the disease was due to high dietary meat and fat as well as lack of alternative food choices while on board.

\section{High propensity for an unhealthy diet}

Seafarers were found to be more vulnerable to unhealthy diet because of the circumstances they are in.
Contributory factors identified included unlimited amount of food servings available and the lack of control over food choices. Most of the time, a buffet is served where there were no restrictions in the amount that they could eat. Some informants also mentioned that the attitude of the chief cook is also contributory to the perceived high number of hypertension. If the chief cook were lazy, he would always prepare meaty and fatty food. Perceived high propensity to hypertension is explained in the following quotations:

"Hypertension is due to food that we were served with, if the chief cook is lazy, he would always serve us adobo (pork in vinegar and soy sauce boiled to tenderness), steak, pata-tim (pork legs cooked in vinegar $\mathcal{E}$ soy sauce), "Jollibee" which means chicken, we call those types of food as 'killing me softly."

Another informant mentioned, "Arthritis comes first before hypertension, this is because of the greater amount of meat in the diet, there were vegetables but limited, sometimes other seafarers do not like vegetables. You have no choice because the food served is adobo, pork bone marrow, and entrails".

Interview responses also revealed that vegetables were usually consumed first just before they begin to show signs of spoilage. Hence, frozen meats and fishes will be served for the rest of voyage unless there is a chance to purchase fresh vegetables in the markets from ports where the ships dock throughout the journey.

Few informants from the dry cargo bulk/tanker vessels also related personally witnessing a case of heart attack happening on board. The informants were aware that heart attack is related to high blood pressure and excessive alcohol intake.

Elevation in liver enzymes specifically SGPT was mentioned by several informants from passenger luxury liners but not among those from dry cargo bulk/tanker vessels. But hepatitis and other liver problems were mentioned by informants from the latter. Some informants from luxury liners attributed SGPT level elevation to high alcohol and fat intake. Some of the verbatim comments were given below.
"Elevated SGPT was because of alcohol and fat intake."
"Drinking alcohol is part of our pastime, it is done simply for fun, $90 \%$ of seamen drink alcohol."

\section{Accessibility of health services and facilities}

\section{Health Services}

The informants were asked about their perceptions related to the accessibility of health services and facilities on 
board. There were no medical nor even paramedical staff on board the dry cargo bulk/tanker vessels. Thus, health services were provided by the second mate who trained on how to manage the common health needs of the seafarers on board such as first aid and basic medical care. In complicated cases, they usually call the nearest hospital where instructions on how to manage patients were received through telephones. For emergency medical situations that may lead to serious or fatal injuries, the captain or second mate could call on the nearest hospital and a helicopter will be sent to fetch the patient for appropriate medical management. Following were quotations from the informants regarding health services:

"We have medications for all types of diseases, we have first aid kits, a complete set of PPE [Personal Protective Equipment], we also have safety briefings on how to use these PPEs. We have a second mate who serves as our doctor on board. If there were serious or fatal injuries like fractures, we contact the nearest hospital and then a helicopter will pick up the patient to be given proper management. If the case can be managed on board, we could receive instruction from the doctor through phone on how to manage emergency cases like heart attack".

Seafarers working in luxury passenger liners were allowed to use the medical facilities and services available for the medical staff when these were needed. Medical doctors and nurses were on board for free consults anytime. Facilities have a complete supply of emergency drugs.

When asked if there were occasions where seafarers were not able to get the health services needed while on board, majority of informants from both groups claimed that health services needed were always readily available.

\section{Health Facilities and Equipment}

Both types of vessels have mini-hospitals which could accommodate a few patients at a time. Passenger luxury liners have a helicopter that could be used to transport patients during emergency cases which was not present in dry cargo bulk/tanker vessels, however, they can always call for helicopter assistance during emergency cases.

Seafarers in both vessels have access to their own gym facilities which have a complete set of work out equipment. However, majority of the informants from dry cargo bulk/tanker admitted not using these facilities because they were often too tired to use them after work. Many would rather sleep, rest, watch movies in their cabins than work out at the gym.

All of the seafarers from the dry cargo bulk/tanker vessels claimed that they have a complete set of Personal Protective Equipment (PPE) on board. Majority of the informants claimed that utilization of PPE is high because there is a person from the crew who monitors its utilization. Nevertheless, there were some who admitted poor compliance in using earmuffs and earplugs. An informant mentioned that:

"There were goggles, earmuffs for too much noise but are not being utilized because of the difficulty of use, others just use cotton plugs as they were perceived to be better than earplugs, earplugs cause pain in the ears. Helmets were required when grinding but were not always used because of the hot sensation it causes."

\section{High satisfaction with the health services and facilities}

The informants were asked to rate their satisfaction with the health services and facilities on board using a scale of 1 to 5 , with 5 as the highest. Majority of informants from dry cargo bulk/tanker vessels gave a mean rating of 4 which indicates a high satisfaction with the health services and facilities on board. The mean satisfaction rating of informants from luxury liner was only 3 and the following were some of the reasons given:

"I only rated health services on board to be 2 because the nurse dispenses medicine which is not effective like Ibuprofen for tooth ache."

"3 only because of absence of $x$-ray, then we had one colleague who died in the ship because of appendicitis."

\section{High coping mechanisms and other psychosocial support}

There were a variety of leisure activities that seafarers engage in to cope with boredom, loneliness and other problems. Off duty, informants from the dry cargo vessels spend most of their time in their cabins sleeping, relaxing, watching DVDs, listening to music, play video games and singing. They also engaged in sports like ping-pong, basketball, softball, and swimming. Sometimes they go to the gym to workout. Gym facilities like barbells, dumbbells, treadmills, stationary bikes, table soccer and mobile bicycles were present and were always available, but, seldom used because of fatigue experienced after work. Drinking sessions were also done during off duty hours. When boredom comes, they could also go fishing in some areas where it was allowed. In this manner, the seafarers did not only get to ease their boredom and loneliness but also had gotten to taste fresh seafood from their catch. See some of the quotations below.

"When on board, we just sleep, watch movies, play video games, or sing. We have videoke and magic sing. When in port, we unwind and visit friends, go to beerhouses, watch strip shows and sometimes, we take our women/sex workers." 
"There is a gym, we can play basketball, softball. There is a swimming pool, dumbbells, treadmills, stationary and mobile bicycles. These were available anytime, however, we seldom use them because we were tired after work and drinking sprees."

"It is only in one's attitude, just believe that you could cope, if you want to aspire for a higher position and financial growth, you can do it."

The coping mechanisms of those working in luxury liners were almost similar to those from the dry cargo/tanker vessels except that the former, on some occasions, had opportunities to attend parties for the crews, going to disco or even to spas.

\section{Informational Support}

Informants from the dry cargo bulk/tanker vessels indicated that guidebook like self-care and HIV/AIDS information were available on board. There were also materials on hypertension, cholesterol and healthy diet. Informants also indicated that these were read when they already ran out of something to read.

'We have reading materials about high blood, cholesterol, and food to eat. We read these materials when we ran out of something to read or after reading FHM."

Materials on safety, first aid were available in the mess hall and in the hospital/clinic. There were times that the captain would casually remind seafarers to reduce weight when needed. There was one who mentioned that if the captain was a Filipino, safety meetings where topics like disease prevention for diseases such as STIs/AIDS on top of work-related problems and concerns were included. Use of condoms to prevent STIs was likewise mentioned to be taught on board.

Most of the informants from luxury liners mentioned that they had access to materials such as posters on STD/AIDS, hypertension, and condom use. There were also lectures or seminars on alcohol and drug awareness, hygiene, healthy diet, basic safety, vaccination, and pregnancy. Condoms and pamphlets were mentioned to be available in the infirmary. Some quotations were as follows:

"We were taught on how to use condoms to prevent HIV, there were pamphlets about pregnancy. There were too many lectures on safety but health issues were not always included, very focused on service and safety."

"We have posters in bulletin boards, there were advertisements about flu and vaccination during flu seasons. We were taught about condom use."
Family Support

With the advent of modern technology, communication with family members has become relatively easier. This was especially true for those in the luxury liners as most of the times, they had access to communication like mobile phones and, therefore, could talk with their families and loved ones anytime they were allowed. They could also make use of the communication facilities of the ship but with corresponding charges. Informants working in dry cargo bulk/tanker vessels also have easy access to communication on board, but they have to pay about US\$ 24 per 27 minutes. They can use their mobile phones if telephone receptions or signals were available.

\section{Discussion and Recommendations}

The objective of this study was to document the Filipino seafarers' lived experiences amidst the circumstances in international shipping vessels, specifically those related to their health conditions, access to and satisfaction with the available health services and facilities, as well as their coping mechanisms.

Seafaring workforce is one of the occupational groups which receive a substantial amount of health- information. Health-information was received at various stages of their work - from the PDOS, during their physical and medical examinations, and until they are finally employed. This cycle is repeated throughout their lifetime until retirement which is determined not by age but by physical fitness to work. HIV/AIDS-related information is mandated by law to be given during the PDOS. Furthermore, they also have free and regular access to health services and facilities either on board or during their medical examinations.

Despite receiving health-information at various work stages, results still showed a preponderance of lifestylerelated conditions and STI-risk behaviors among this population group which is consistent with what was found in other studies. ${ }^{8,9,11,12}$ These conditions were either observed to have happened to their co-workers or were personally experienced by at least one of them. This seeming inconsistency between good knowledge and poor practice could be explained by the fact that good knowledge of a health condition is not always translated into an ideal practice or behavior and that providing access to health services and facilities does not always equate to its utilization. It is important to study other factors that could influence this knowledge-behavior gap in order to improve the health of the seafarers. An example of this is how to improve the utilization of on-board health and wellness facilities such as the use of incentives and linking good/positive indicators to adherence to healthy lifestyle programs.

Seafarers from both types of vessels were able to cope up with the different work-related stresses on board. Coping 
mechanisms were made relatively easier with better communication facilities and equipment, availability of leisure facilities, materials and gadgets, informational support available on board and family support provided by the their loved ones. This finding reflects the adaptability of Filipino seafarers amidst difficult circumstances which is consistent with what was found by other authors. ${ }^{2,8}$

In light of the above findings, it is recommended that an integrated healthy lifestyle policy be formulated and implemented by the shipping management. This policy can include provisions that promote healthy diet among seafarers within the context of the seafaring environment e.g. long period of travel at sea, etc. The healthy lifestyle policy should also include provisions that will promote physical activity and exercise among the staff and crew with due regard to the work shift environment in the ship.

This policy should be supported by more appealing, durable and culturally appropriate information, education and communication (IEC) materials which can be provided in strategic locations such as mess halls and crew cabins. Materials in video format can be distributed to seafarers to be viewed during assemblies and in their cabins.

The above conclusions and recommendations should be taken in the light of the study's possible limitations. The selection of only one industrial clinic as the study site raises the question on whether or not the data gathered in this particular clinic is representative of the common seafarers experience. Since this industrial clinic is one of the biggest in Metro Manila and caters to various international shipping companies, it is also possible that the lived experiences of the study informants do not vary much with those from other industrial clinics. It is the goal of this qualitative study to provide more depth and breadth in the ongoing discussion of these important issues so that we can better understand the lived experiences of Filipino seafarers.

\section{References}

1. Pinoy sailors remit over US\$ 4 billion in 2011 [Online]. 2012 [cited 2012 Feb]. Available from http://www.gmanetwork.com/news/ story/249538/pinoyabroad/pinoy-sailors-remit-over-4-billion-in-2011.

2. Swift O. Flexible Filipinos: myths and realities about Filipino seafarers: Understanding the role of seafarers' partners in retaining quality crew. Anthropology, Goldsmiths University of London.

3. BIMCO/ISF Manpower 2005 Update. The world demand for and supply of seafarers, Institute for Employment Research, University of Warwick, December 2006.

4. Hansen HL. Surveillance of deaths on board Danish merchant ships, 1986:implications for prevention. Occup Environ Med. 1996; 53(4):26975.

5. Roberts SE, Hansen HL. An Analysis of the causes of mortality among seafarers in the British merchant fleet (1986-1995) and recommendations for their reduction. Occup Med (Lond). 2002; 52(4):195-202.

6. Nielsen D, Hansen HL, Gardner BM, Jungnickel D. Deaths due to disease of seafarers on board Singapore ships. Int Marit Health. 2000; 51(1-4):20-9.
7. Collins A, Matthews V, McNamara R. SIRC/Center for Occupational and Health Psychology. Fatigue, health and injury among seafarers and workers on offshore installations: A Review. September 2000; pp. 22-23.

8. Saniel OP, Tolabing CC, Lebanan-Dalida MO. HIV Prevalence, Risks and Vulnerabilities of Cavite Overseas Filipino Workers, Their Spouses and Their Children: Baseline Research for Programme Area 1 of the Joint UN Program on HIV and Migration, Manila: DOH. 2010a. pp. 81-90.

9. Kaerlev L, Dahl S, Nielsen PS, et al. Hospital contacts for chronic diseases among Danish seafarers and fishermen: A population-based cohort study. Scand J Public Health. 2007; 35(5):481-9.

10. Armstrong W. Noumea, New Caledonia: Secretariat of the Pacific Community. HIV/AIDS and STD among Seafarers in the Pacific Region. In: Proceedings of the 1st Pacific Regional HIV/AIDS and STD Conference (1st: 23-25 February, 1999: Nadi, Fiji) Noumea, New Caledonia. 2000. pp. 34-36.

11. Suñas L. Remedios AIDS Foundation, Inc., The vulnerabilities of Filipino seafarers to HIV/STIs [Online]. 2003 [cited 2012 July]. Available from http://www.remedios.com.ph/html/mk3q2003_tvof.htm.

12. Dulay HB. Of kilatis, women and Filipino seafarers: perceptions of Filipino seafarers on sexually-transmitted disease, its prevention and treatment. A Master's Thesis. Faculty of Social and Behavioral Sciences, Universiteit van Amsterdam. 2004.

13. Binghay VC. School of Labor and Industrial Relations, University of the Philippines, Ensuring occupational health and safety for overseas Filipino seafarers [Online]. [cited 2012 July]. Available from http://www.freewebs.com/upsolair/Ensuring\%20Occupational\%20Healt h\%20and \%20Safety\%20for\%20Overseas\%20Filipino\%20Seafarers.pdf.

14. Polit D, Beck C. Nursing Research: Principles and Methods, $7^{\text {th }}$ ed. Philadelphia: Lippincott Company; 2004. p. 253.

15. Family Health International, Qualitative Research Methods: A Data Collector's Field Guide. Module 1 Qualitative Research Methods Overview. p. 5.

16. Sandelowski M. Sample size in qualitative research. Res Nurs Health. 1995; 18(2):179-83. 